\title{
Endoscopic ultrasonography-guided hepaticogastrostomy with parenchymal metal stent placement
}

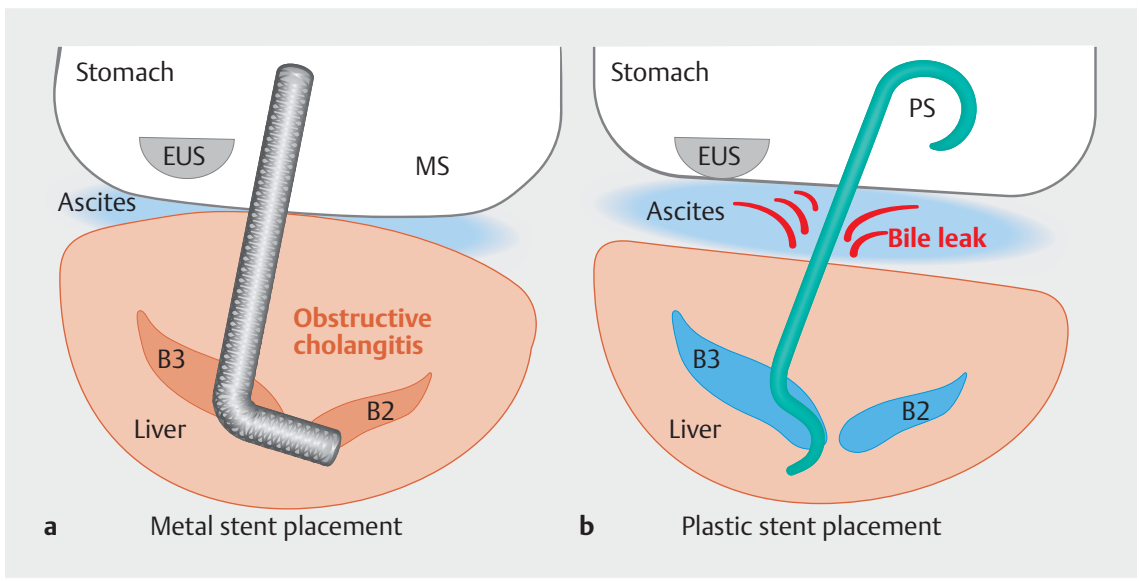

- Fig. 1 Stent placement in endoscopic ultrasonography-guided hepaticogastrostomy. a There is a risk of obstructive cholangitis if a metal stent is placed at the same site as previous stents. b There is a risk of bile peritonitis when only a plastic stent is placed. EUS, endoscopic ultrasound; MS, metal stent; PS, plastic stent.
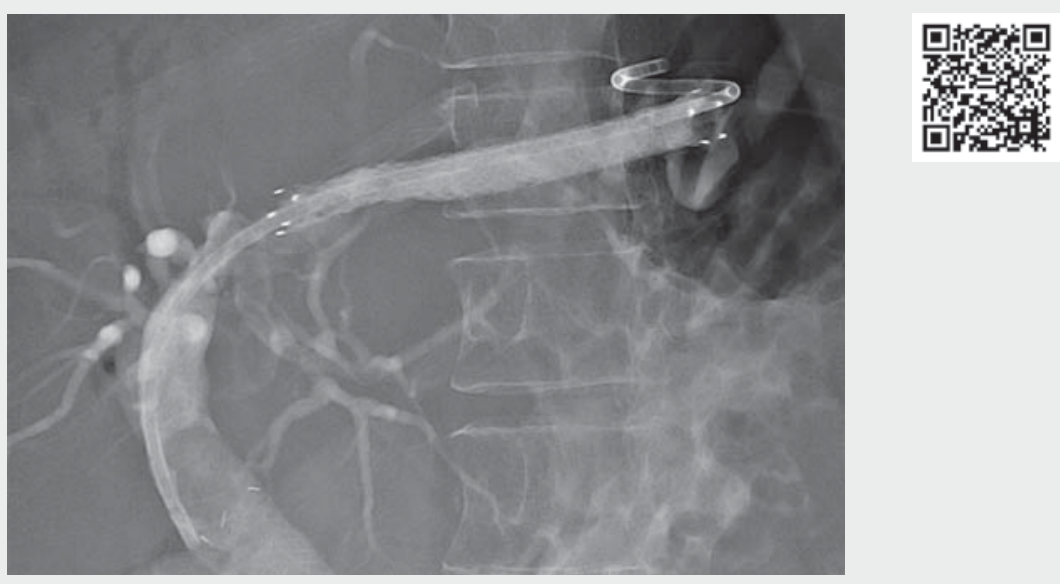

$\checkmark$ Video 1 Endoscopic ultrasonography-guided hepaticogastrostomy with parenchymal metal stent placement and plastic stent placement in the bile duct.

Endoscopic ultrasonography-guided hepaticogastrostomy (EUS-HGS) is performed to create a biliary drainage route for malignant distal biliary obstruction during complicated endoscopic retrograde cholangiopancreatography $[1,2]$. However, when EUS-HGS is performed in patients with cholangitis and ascites, metal stent placement may cause periph- eral obstructive cholangitis ( $\mathbf{F i g . 1 a ) , ~}$ while plastic stents may cause biliary peritonitis due to bile leakage into the ascites (> Fig.1b) [3,4]. To address this challenge, we implemented a novel EUS-HGS method of hepatic parenchymal metal stent placement with plastic stent in the bile duct ( $\mathbf{F i g . 2}$ ), which proved to be effective ( $\triangleright$ Video 1 ).

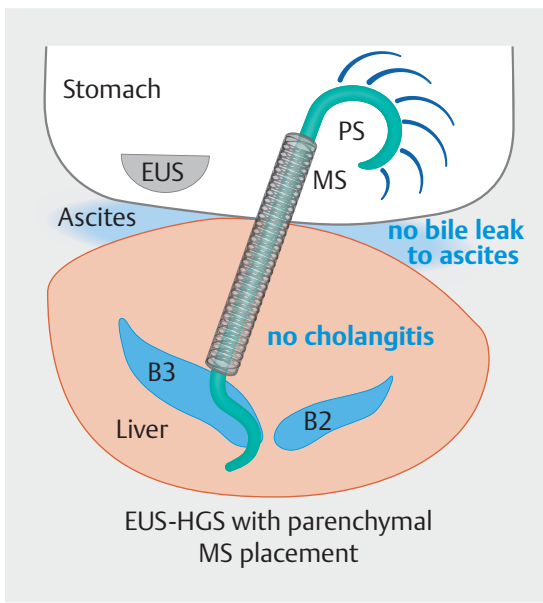

- Fig. 2 Hepatic parenchymal metal stent placement with plastic stent in the bile duct prevented obstructive cholangitis and biliary peritonitis. EUS, endoscopic ultrasound; MS, metal stent; PS, plastic stent.

Our patient was a 64-year-old woman with biliary and duodenal stents for relieving the obstruction of the distal bile duct and duodenum due to unresectable pancreatic cancer. She developed cholangitis due to biliary stent dysfunction ( $\triangleright$ Fig.3). We decided to perform EUSHGS with hepatic parenchymal metal stent placement using a laser cut-type fully covered metal stent (LFCMS) along with plastic stent placement in the bile duct.

After puncturing B3 with a 19-gauge needle using a convex ultrasound endoscope, a 0.025 -inch guidewire was placed into the common bile duct, and a 6-mm balloon was used to dilate the fistula. Subsequently, the LFCMS $(8 \mathrm{~mm}$ diameter, $8 \mathrm{~cm}$ length, X-Suit NIR Biliary Metallic Stent; Olympus Medical Systems, Tokyo, Japan) was deployed, with the stent end in the hepatic parenchyma slightly outside the bile duct, while being careful not to occlude the bile duct with the stent. After confirming the position of the metal stent by contrast to ensure that it was not in the bile duct, a 7-Fr plastic stent (TYPE IT; 

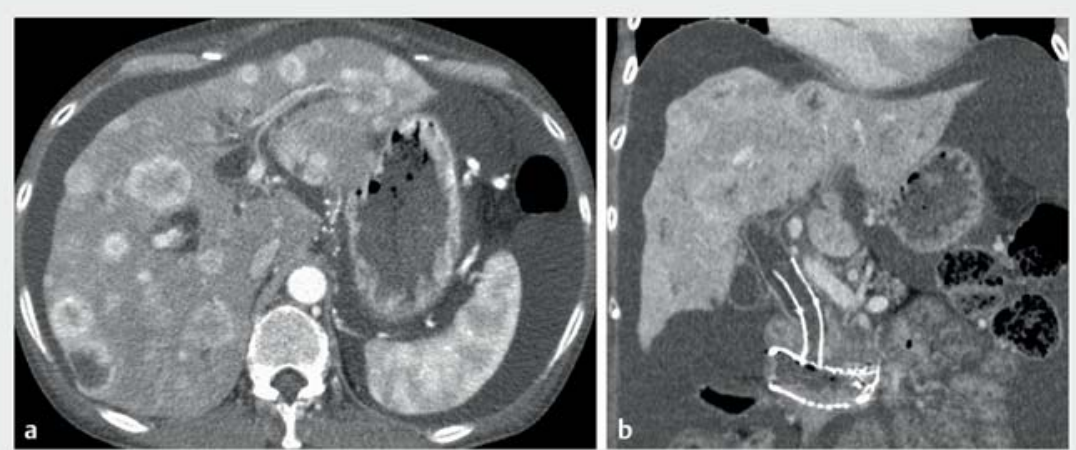

- Fig. 3 Imaging findings before the procedure. a Computed tomography (CT) showing dilated intrahepatic bile duct, with multiple liver metastases and ascites due to pancreatic cancer. b CT showing occluded duodenal and distal bile duct stent.
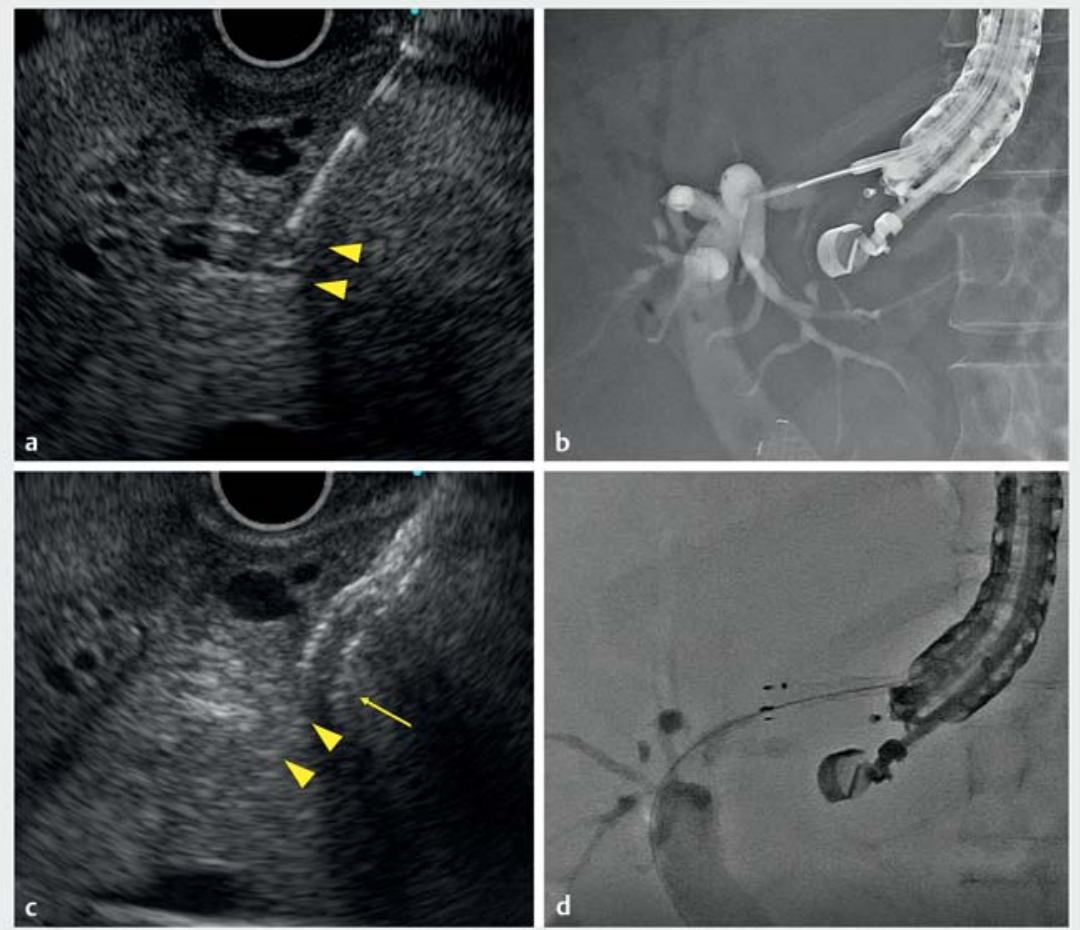

-Fig.4 Endoscopic ultrasonography (EUS)-guided hepaticogastrostomy with parenchymal metal stent placement. a EUS image: B3 (arrowheads) was punctured using a fine-needle aspiration (FNA) needle. b Fluoroscopic image: B3 was punctured using an FNA needle. c EUS image: a laser cut-type fully covered metal stent (arrow) was deployed in the hepatic parenchyma. Arrowheads indicate the bile duct wall (B3). d Fluoroscopic image: the metal stent deployed from the scope in the hepatic parenchyma.
Gadelius Medical, Tokyo, Japan) was placed in the bile duct ( $>$ Fig.4, $>$ Fig.5). The patient's clinical condition improved after the procedure.

The LFCMS is retained in place more easily than the braided-type metal stent. Therefore, LFCMS was considered suitable for this EUS-HGS method in a patient with cholangitis and ascites.

Endoscopy_UCTN_Code_TTT_1AS_2AD

\section{Acknowledgement}

This work was supported in part by The National Cancer Center Research and Development Fund (31-A-13) and (2021-S-5).

\section{Competing interests}

The authors declare that they have no conflict of interest.

The authors

Motohiro Yoshinari' ${ }^{1}$, Susumu Hijioka', Takuji Okusaka ${ }^{1}$, Yutaka Saito ${ }^{2}$

1 Department of Hepatobiliary and Pancreatic Oncology, National Cancer Center Hospital, Tokyo, Japan

2 Department of Endoscopy Division, National Cancer Center Hospital, Tokyo, Japan

\section{Corresponding author}

\section{Susumu Hijioka, MD, PhD}

Department of Hepatobiliary and Pancreatic Oncology, National Cancer Center Hospital, 5-1-1 Tsukiji, Chuo-ku, Tokyo 104-0045, Japan shijioka@ncc.go.jp 

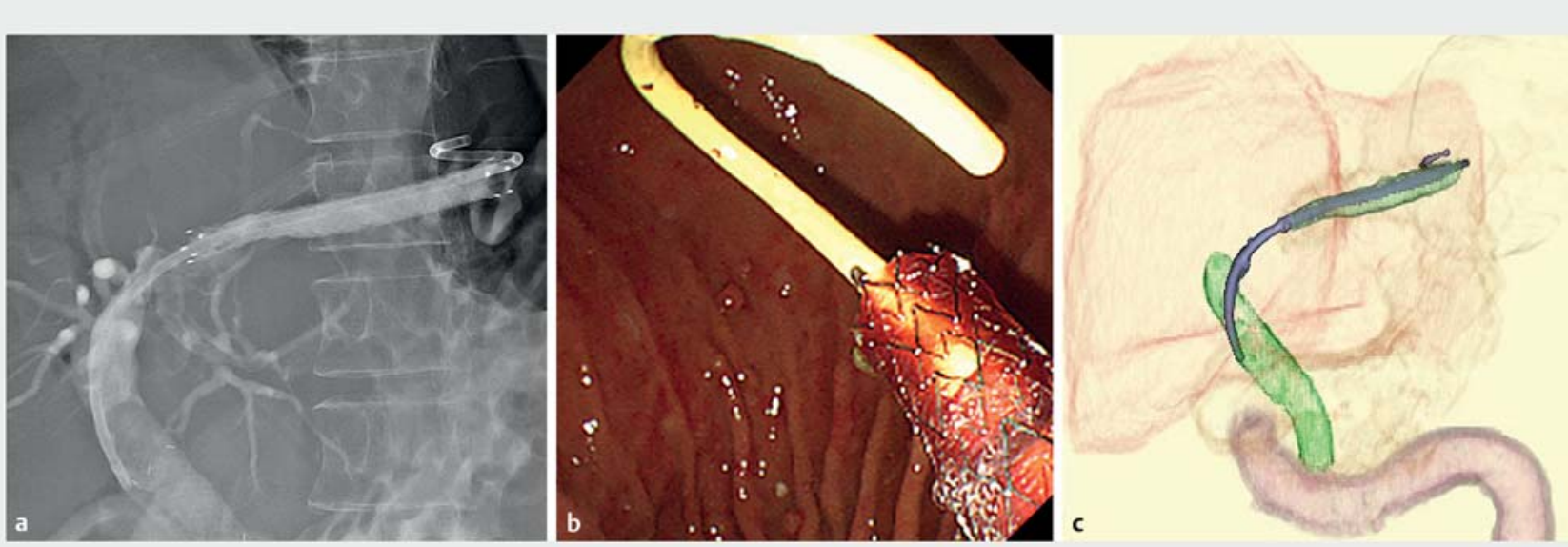

- Fig. 5 Plastic stent placement in the bile duct. a Fluoroscopic image: a plastic stent was placed in the bile duct. b Endoscopic image after stent placement. c Three-dimensional reconstruction.

\section{References}

[1] Dumonceau JM, Tringali A, Papanikolaou IS et al. Endoscopic biliary stenting: indications, choice of stents, and results: European Society of Gastrointestinal Endoscopy (ESGE) Clinical Guideline - updated October 2017. Endoscopy 2018; 50: 910-930

[2] Leung Ki EL, Napoleon B. Endoscopic ultrasound-guided biliary drainage: a change in paradigm? World J Gastrointest Endosc 2019; 11: 345-353

[3] Khan MA, Akbar A, Baron TH et al. Endoscopic ultrasound-guided biliary drainage: a systematic review and meta-analysis. Dig Dis Sci 2016; 61: 684-703
[4] Nakai Y, Sato T, Hakuta R et al. Long-term outcomes of a long, partially covered metal stent for EUS-guided hepaticogastrostomy in patients with malignant biliary obstruction (with video). Gastrointest Endosc 2020; 92: 623-631

\section{Bibliography}

Endoscopy 2022; 54: E719-E721

DOI 10.1055/a-1759-2479

ISSN 0013-726X

published online 7.3.2022

(c) 2022. Thieme. All rights reserved.

Georg Thieme Verlag KG, Rüdigerstraße 14, 70469 Stuttgart, Germany

\section{ENDOSCOPY E-VIDEOS}

https://eref.thieme.de/e-videos

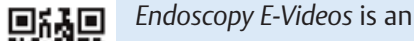
open access online section, 靣: reporting on interesting cases and new techniques in gastroenterological endoscopy. All papers include a high quality video and all contributions are freely accessible online. Processing charges apply (currently EUR 375), discounts and wavers acc. to HINARI are available.

This section has its own submission website at https://mc.manuscriptcentral.com/e-videos 